\title{
Numerical Simulation of Riverbank Failure in Lower Reaches of Yangtze River
}

\author{
CHEN Kaihua ${ }^{1, a}$, XIA Yunfeng ${ }^{1, b}$, WEN Yuncheng ${ }^{1, c}$, XU Hua ${ }^{1, d}$, LIU \\ Xingtong ${ }^{1, e}$ \\ 134th HuJuGuan, Nanjing Hydraulic Research Institute, Nanjing, JiangSu Province, China \\ a415304706@qq.com, byfxia@126.com, c443645791@qq.com, d27282036@qq.com, \\ e27282036@qq.com
}

Keywords: riverbank failure, numerical simulation, Yangtze River, mechanism, boundary shear stress method

Abstract. In this paper, in order to solve the problem of riverbank failure in Yangtze River estuary, the reason of the formation of riverbank failure and mechanism at the estuary of the Yangtze River was first analyzed. Then base on the newly derived formula recently by Chen et al, a two-dimensional riverbank failure numerical code was established, and this code was applied to the Minzhu Shoal and Langshan Shoal in the area of the estuary of the Yangtze River. The results show that the simulation results are in good agreement with the measured data.

\section{Introduction}

Riverbank failure in the Yangtze River estuary area is a major problem plaguing numerous channel regulation researchers for a long time. There are many influencing factors of riverbank failure. In addition to the reason of geological conditions of the riverbank, section morphology, river water flow and groundwater seepage erosion, There are ship's navigation, human-made dredging, and sudden load factors, as well as rainfall, vegetation and other factors. The numerical model prediction research on riverbank failure began in the 1960s. The recent numerical model for riverbank failure combine a one-dimensional empirical analytical riverbank failure model, a two-dimensional riverbank failure numerical model, and a three-dimensional riverbank failure model. The numerical model prediction research on riverbank failure began in the 1960s. The recent numerical model for riverbank failure combine a one-dimensional empirical analytical riverbank failure model, a two-dimensional riverbank failure numerical model, and a three-dimensional riverbank failure model. The classic empirical analysis (one-dimensional) riverbank failure numerical model includes Odgaard model, Liang Zhiyong and Yin Xueliang model, CONCEPTS 1.0-2.0 software, RVRMEANDER software, Abad numerical model, GSTARS, BSTEM model. The two-dimensional riverbank failure numerical model combines the water-sediment model with the riverbank failure model by considering the interaction between the water-sediment model and the riverbank deformation. The classical two-dimensional riverbank failure model includes Xia Junqiang model, Shao Xuejun model, and Chen Dong model and the CCHE2D model developed by the University of Mississippi. Three-dimensional riverbank failure model includes models developed by Jia and Huang. This paper proposes to use the formula proposed by Chen et al to improve the two-dimensional riverbank failure model, and then apply the improved two-dimensional riverbank failure model to the simulation of riverbank failure in the lower reaches of the Yangtze River, and the mechanism of the riverbank failure process in the lower reaches of the Yangtze River was analyzed.

\section{Mechanism of the riverbank failure in lower reaches of Yangtze River}

In recent years, the Yangtze River estuary area has experienced severe riverbank failure many times, most of the riverbank failure is in the form of strip collapsing and arc collapsing, this phenomenon has posed a tremendous threat to the lives and property of the people living around the riverbank. In this study, typical riverbank failure cross-sections were chosen to study in the Yangtze River estuary; the 
location is as Fig.1 shows. As depicted from Fig.1, it shows the plan view of estuary area of Yangtze River from Jiangyin to Nantong, the area studied in this research is the MinZhu Shoal and the LangShan Shoal. Minzhu Shoal is located in LiuHaiSha Waterway, and it is influenced a lot by circulation flow and LangShan Shoal from Tongzhousha East Waterway which experienced severe riverbank lateral erosion. This study will focus on these two areas, five cross section named MZS2, MZS3, LSS1, LSS2, LSS3. In Fig.1, in the area of Minzhu shoal, from upstream to downstream, the name of the cross-section is MZS2, MZS3, respectively. In the area of Langshan shoal, from upstream to downstream, the name of the cross-section is LSS1, LSS2, LSS3. Also, from Fig.1 we know that there is continuous circulation flow in the Jiangyin--Nantong river reach of the Yangtze River, at the same time, the soil layer in the riverbank presents a typical dual structure of the complex geological conditions distribution. In addition, sediment concentration in the upstream and downstream streams decreased a lot after the operation of TGP which triggered the phenomenon of riverbank instability, and riverbank failure occurred. However, the MinZhu Shoal and the LangShan Shoal which selected in this study experienced the phenomenon of riverbank instability and thalweg offset, as shown in Figure 2. In Fig.2, it is found that there is apparent main thalweg skewing in the Yangtze Estuary area towards the concave bank and riverbank failure occurred in Minzhu Shoal. Through analysis, the reason why the riverbank failure frequently occurred in Yangtze River estuary is as follows: the first reason is the adjustment of river regime, the second reason is the circulation flow in meandering channels, the third point is the typical dual structure of the complex geological conditions, the fourth point is the change of incoming water and sediment, the fifth point is the flood effect.

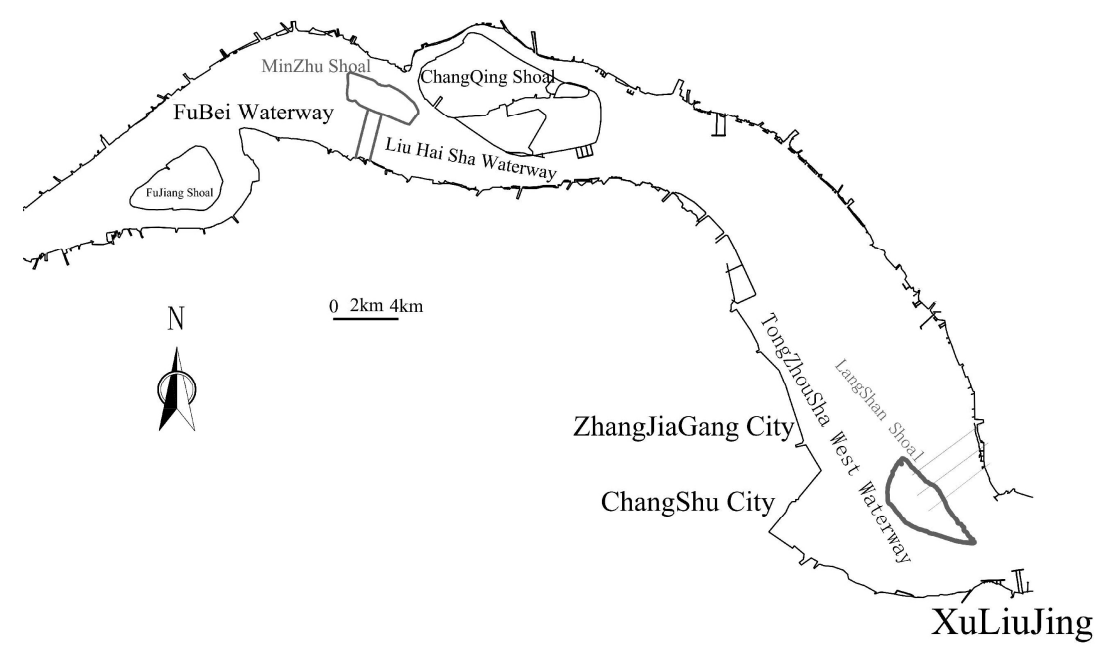

Fig.1 Plan view of the ChengTong reach of the Yangtze River
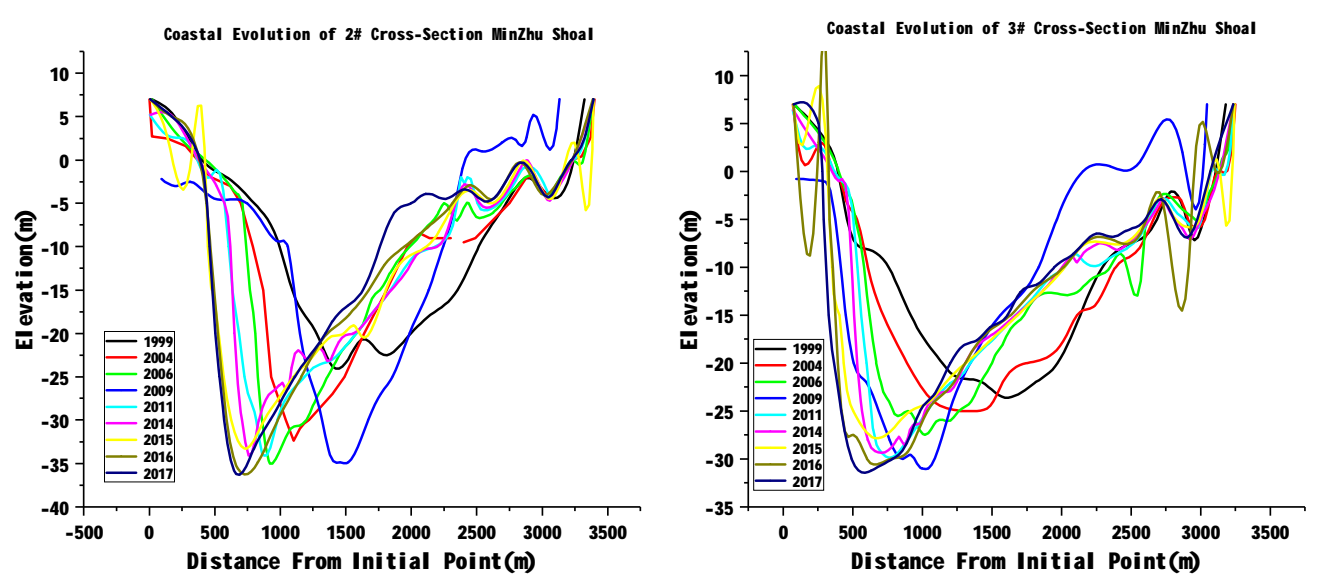

Fig.2 Change of section morphology at the estuary area of Yangtze River observed from 1999 to 2017 


\section{The establishment of riverbank failure numerical model}

The two-dimensional riverbank failure numerical model applied in this study is divided into three submodels, namely flow model, sediment model and the riverbank failure model.The two-dimensional flow model applied two-dimensional shallow water equation to discretely solve the water level and velocity distribution near the riverbank and uses Lien's second-order empirical formula to simulate the secondary flow. The two-dimensional non-uniform sediment model comprehensively considers suspended sediment transport, bed load transport, and bed deformation. The non-homogeneous riverbank failure model adopts the mass failure model proposed by Langodoen and some improvement had been proposed by using the boundary shear stress model raised by Chen et al to improve the riverbank failure model. In this way, the model can more accurately calculate the erosion rate of the riverbank and predict the change of riverbank morphology. The governing equation of the riverbank model is as follows.

$$
\begin{aligned}
& \frac{\partial \zeta}{\partial \mathrm{t}}+\frac{\partial p}{\partial x}+\frac{\partial q}{\partial y}=0 \\
& \frac{\partial p}{\partial t}+\frac{\partial(\beta p U)}{\partial x}+\frac{\partial(\beta p V)}{\partial y}=f q-g H \frac{\partial \zeta}{\partial x}-\frac{g p \sqrt{p^{2}+q^{2}}}{H^{2} C^{2}}+\varepsilon\left(\frac{\partial^{2} p}{\partial x^{2}}+\frac{\partial^{2} p}{\partial y^{2}}\right) \\
& \frac{\partial q}{\partial t}+\frac{\partial(\beta q U)}{\partial x}+\frac{\partial(\beta q V)}{\partial y}=-f p-g H \frac{\partial \zeta}{\partial y}-\frac{g q \sqrt{p^{2}+q^{2}}}{H^{2} C^{2}}+\varepsilon\left(\frac{\partial^{2} q}{\partial x^{2}}+\frac{\partial^{2} q}{\partial y^{2}}\right) \\
& \frac{\partial \mathrm{h}}{\partial t}+\frac{1}{1-P}\left(\frac{\partial q_{x}}{\partial x}+\frac{\partial q_{y}}{\partial y}\right)=0 \\
& q_{s}=C_{m}\left[\left(\frac{\rho_{s}}{\rho}-1\right) g\right]^{0.5} d_{50}^{1.5}\left[\left(\frac{n}{n}\right)^{1.5} \theta-\theta_{c}\right]^{1.5} \\
& \theta=\frac{\tau_{b}}{\left(\rho_{s}-\rho\right) g d_{50}} \\
& \theta_{c}=\frac{\tau_{c}}{\left(\rho_{s}-\rho\right) g d_{50}} \\
& n^{\prime}=\frac{d_{90}^{\frac{1}{6}}}{26} \\
& \tau_{b}=\rho\left[8.1\left(\frac{H}{K_{s}}\right)^{\frac{1}{6}}\right]^{-2} U^{2} \\
& K_{s}=2.95 D_{84} \\
& \tau_{b}=F r^{2} \rho g H S_{0}-\left(1-F r^{2}\right) \rho g H \frac{\partial \zeta}{\partial s} \\
& w=\frac{c_{l} t\left(\tau_{b}-\tau_{c}\right) e^{-0.013 \tau_{c}}}{\gamma_{\text {bank }}} \\
& \tau_{b}=0.76 \gamma_{\text {bank }} R S_{0} \\
& F_{s}=\frac{\sum_{k=1}^{k}\left(c^{\prime} L+F_{w} \sin \alpha \tan \phi^{\prime}-\mu_{w} L \tan \phi^{b}\right)_{k}}{\sum_{k=1}^{k}(W+P \cos \alpha)_{k}}
\end{aligned}
$$


In the above equation, $\zeta$ refers to the water surface elevation $(m), H$ refers to the water depth, h refers to the bed elevation, $\mathrm{U}, \mathrm{V}$ refer to the depth-average velocity in the direction of $\mathrm{x}$ and $\mathrm{y}, \mathrm{p}$ and $\mathrm{q}$ refer to the unit discharge in the direction of $\mathrm{x}$ and $\mathrm{y} . \beta$ equals to $1.016, \mathrm{f}$ refers to Coriolis force, $\mathrm{g}$ refers to acceleration of gravity, $\mathrm{C}$ refers to Chezy coefficient, $\varepsilon$ refers to the depth-average eddy viscosity. $\mathrm{P}$ refers to the porosity of the sediment, $q_{x}$ refers to the unit volume sediment discharge in $\mathrm{X}$ direction, $q_{y}$ refers to the unit volume sediment discharge in $\mathrm{Y}$ direction. $q_{s}$ refers to the unit volume of the bed load transport in $X$ direction, $\rho_{s}$ refers to sediment density, $\rho$ refers to water density, $\mathrm{n}$ refers to the Manning coefficient, $\theta$ refers to the sediment particle flow parameters, $\tau_{b}$ refers to the bed shear stress, $\tau_{c}$ refers to the critical shear stress, $d_{50}$ refers to the median particle diameter. $\omega$ refers to the erosion rate of retreat of bank slope peak. In this research, the boundary shear stress $\tau_{b}$ in Eq.9 will be replaced by the newly derived semi-empirical semi-experimental expression proposed by Chen et al(2018) to predict the boundary shear stress on the slope on the riverbank. The critical shear stress can be predicted by JET test or the semi-empirical expression.

\section{Modelling of the riverbank failure in the lower reaches of Yangtze River}

In this section, the re-evaluation and prediction of the riverbank evolution in Minzhu Shoal and Langshan Shoal in the Chengtong reach of the lower reaches of the Yangtze River had been carried out and the comparison between the numerical simulation results and the actual field measurements had been proceed.Minzhu Shoal is located in the LiuhaiSha water channel in the Chengtong reach, adjacent to Fujiangsha and Shuangjiansha. The tidal phenomenon is more obvious and the bottomland develops. The influence of the secondary flow was obvious and the concave bank experience severe damage. The depth of the undercut reached a local area of $10.5 \mathrm{~m}$. At the same time, due to the drastic reduction in the amount of incoming sand from the upper reaches of the river, the adjustment of rivers channel is obvious and the thalweg is deflected to the concave bank. The riverbank failure phenomenon is obvious in this area.As depicted in Fig. 3, a comparison between the measured results of the riverbank evolution and the calculation results of the numerical model for the Minzhu Shoal and Langshan Shoal had been established. From Figure 3, we can see that the measured riverbank evolution are in good agreement with the numerical simulation results. There are only differences in tiny areas, which proves that the establishment of an improved two-dimensional riverbank failure numerical model can be used for future prediction. When considering the impact of riverbank protection, there was no obvious phenomenon of riverbank failure in the left and right riverbank of the typical cross-section of Langshan Shoal, but the depth of erosion on the toe of the left bank of Langshansha intensified, and the slope of the bank on the left became steeper, resulting in bank collapse. At the same time, in the left bank, the erosion of the riverbank toe also appeared. The possible reason for this phenomenon is that the riverbank toe has lost the protection of the collapsed sediment from the riverbank. Under the comprehensive influence of the adjustment of the river regime and the deflection of the thalweg, the erosion of the toe of the left riverbank is intensified. From the calculation results, it can be seen that the Langshan Shoal Protection Project has a rather obvious inhibitory effect on the evolution of the typical riverbank and the change of the riverbank evolution. The existence of the bank protection project also promotes deep groove migration and thalweg deflection. 

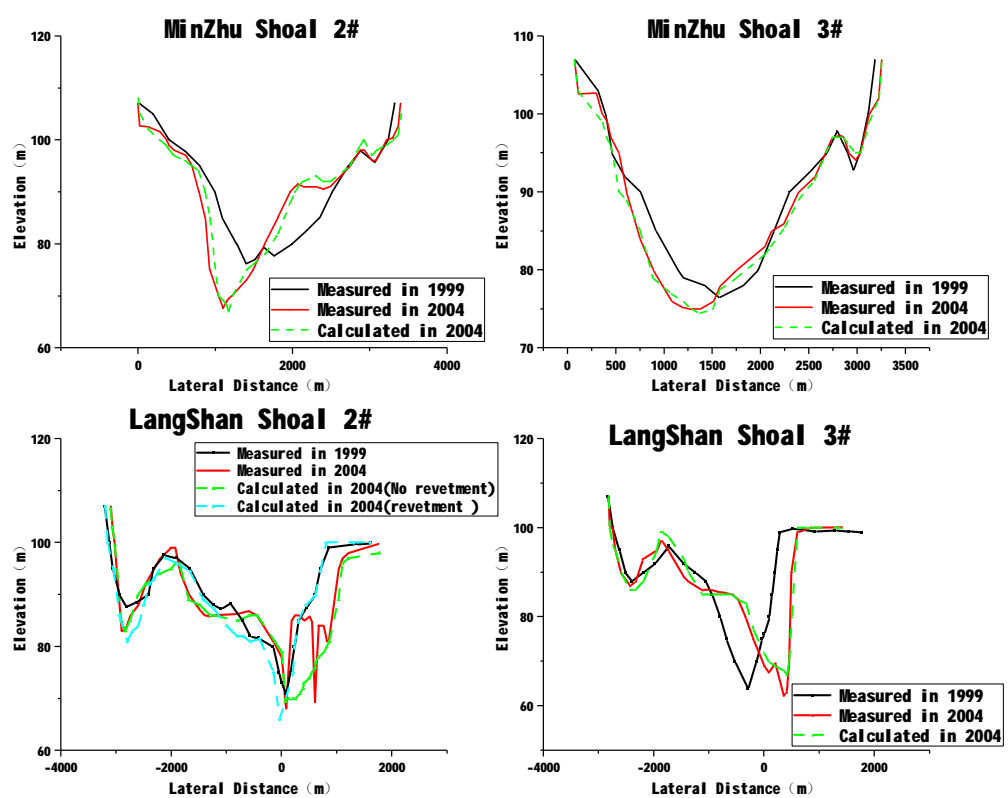

Fig.3 The Verification of the the riverbank evolution of Minzhu Shoal and Langshan Shoal
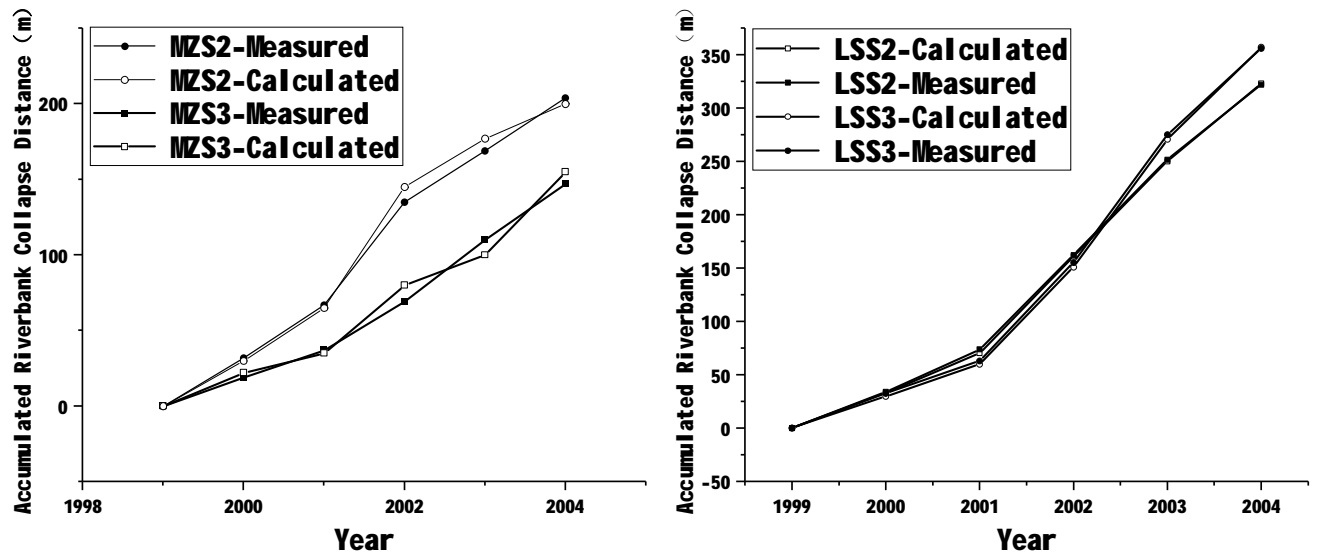

Fig.4. The Verification of the Accumulated Collapse Distances of the riverbank slopes at the Minzhu Shoal and Langshan Shoal
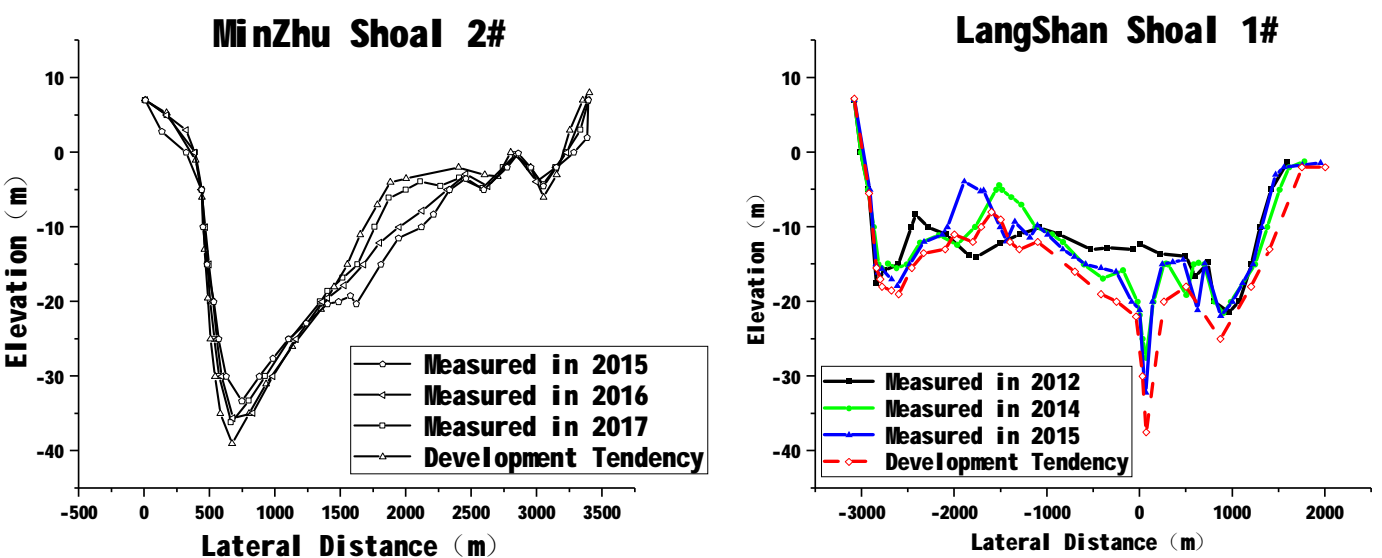

Fig.5. The development tendency of riverbank evolution in Minzhu shoal and Langshan Shoal

The following analyses fucus on the future development of the MZS2\# cross-section morphology and the LSS1\# cross-section morphology. According to the riverbank failure model simulation, the evolution of the riverbank failure shows that the change of the cross-section shape corresponds to the change of the mainstream and river regime adjustment. Due to the effect of secondary flow, the mainstream is deflected to the concave bank, and the deep groove is obviously deep. The convex bank gradually deposits, and the shape of the cross-section changes from " $U$ " to "V".In the downstream of 
the meandering channel, due to the centering of the mainstream, the erosion appears in the right side of the riverbank and the deposition appears in the left side of the bank. Basically, it maintains relatively stable characteristics. The riverbank failure seen in the left side of the Langshan Shoal will continue. The erosion at the toe of the left bank intensifies, and the deep trough near the left bank continues. The reason for the occurrence of left-bank-evolution is that the main trough is stable on the left side of the Langshan Shoal thus causing the left bank continue to collapse significantly. The riverbed shows a tendency of scouring and silting, and the amount of back silting gradually weakens.

\section{Conclusions}

The riverbank failure numerical study was conducted on the lower reaches of the Yangtze River. Minzhu Shoal and Langshan Shoal in the lower reaches of the Yangtze River were selected for analysis. Firstly, the evolution of the riverbank and the mechanism of the riverbank failure have been analyzed. It has been concluded that changes in incoming water and sediment in the lower reaches of the Yangtze River caused by the operation of the TGP and the adjustment of the river according to the evolution of the lower reaches of the Yangtze River. Afterwards, a two-dimensional riverbank failure numerical model was established. The model was applied in the study of the prediction of riverbank failure in the lower reaches of the Yangtze River. The study shows that this model can simulate the evolution precisely. The error range is within the allowable range and it can be recommended for use in engineering applications.

\section{Acknowledgements}

This work was financially supported by the National Key R\&D Plan(2016YFC0402307) in China, Key Fund Project of the Nanjing Hydraulic Research Institute(Y217007) in China and National Natural Science Fund(51779149) in China

\section{References}

[1] Chen Kaihua et al., Experimental Research on Boundary Shear Stress in Typical Meandering Channel[J]. CHINA OCEAN ENGINEERING, 2018. 32(3): p. 365-373

[2] Hao S-Y, Xia Y-F, Xu H. Experimental study on the bed shear stress under breaking waves[J]. CHINA OCEAN ENGINEERING, 2017, 31(3): 308-316.

[3] Lammers R W, Bledsoe B P, Langendoen E J. Uncertainty and sensitivity in a bank stability model: implications for estimating phosphorus loading $[\mathrm{J}]$. Earth Surface Processes and Landforms, 2017, 42(4): 612-623.

[4] Luppi L, Rinaldi M, Teruggi L B, et al. Monitoring and numerical modelling of riverbank erosion processes: a case study along the Cecina River (central Italy)[J]. Earth Surface Processes and Landforms, 2009, 34(4): 530-546. 